\title{
OUVIDORIA: FERRAMENTA ORGANIZACIONAL ESTRATÉGICA
}

\author{
Aline Andréa Atalla Pereira ${ }^{1}$ \\ Priscilla de Oliveira Silva ${ }^{2}$ \\ Riane Soares do Vale Amorim ${ }^{3}$
}

\begin{abstract}
Resumo
Nos hospitais, com a introdução dos sistemas de Gestão de Qualidade e a busca pelos selos de acreditação, tendência mercadológica e competitiva, percebeu-se a necessidade de um canal para ouvir o cliente, haja vista a gama de informações extraídas das manifestações que possibilitam a melhoria dos processos, visando a segurança tanto dos pacientes quanto de colaboradores. Ouvir é importante e necessário, pois é uma fonte valiosa de informações para as organizações que querem garantir uma boa fatia do mercado e, consequentemente, a sua sustentabilidade. O setor foi estruturado com o modelo habitualmente utilizado nas Ouvidorias e implantado em 2014. Prevê uma Ficha de Análise de Manifestação, que recebe o registro da manifestação dos diversos canais de comunicação, como Sua Opinião (formulário disponível aos clientes), Fale Conosco (via site do hospital), Reclame Aqui, Telefone, Presencial, as Seguradoras e as Redes Sociais. Posteriormente, a manifestação recebe uma classificação "inicial": Reclamação, Elogio, Sugestão, Solicitação, Informação, Denúncia, Expressão Livre; e também uma classificação "técnica", quando relacionada a Estrutura, Pessoas, Processo, e outras denominações ajustadas à demanda da instituição.
\end{abstract}

Palavras-chave: Ouvidoria. Melhoria. Processos. Experiência do Consumidor.

\section{DOI:10.37814/2594-5068.2018v1.p29-35}

1 Gerente de operações. Nutricionista formada pela Universidade São Camilo. MBA Controller pela FIPECAFI-USP.

2 Analista de Ouvidoria formada em Administração em Recursos Humanos pela UNINOVE.

3 Enfermeira formada pela UNINOVE, com especialização em cardiologia pela Universidade Federal de São Paulo (Unifesp). 


\begin{abstract}
In hospitals, with the introduction of quality management systems and the quest for accreditation seals, market and competitive trend, realized the need for a channel to listen to the customer, given the range of information extracted from the demonstrations that enable the improvement of processes, aimed at the safety of patients as employees. Hearing is important and necessary, as it is a valuable source of information for organizations that want to secure a good slice of the market and, consequently, their sustainability. The industry was structured with the model commonly used in the Ombudsman's Offices and deployed in 2014. It provides an analysis of Manifestation, which receives the manifestation of various communication channels, such as Your Opinion (form available to customers), Contact Us (via the hospital site), Submit a Complaint, Phone, In Person, Insurers and Social Networks. Later, the demonstration is given a rating: Complaint, Suggestion, Request, Information, Denunciation, Free Expression, and also a "technical" classification when related to the Structure, People, Process, and other denominations, adjusted to the demand of the institution.
\end{abstract}

Keywords: Ombudsman's Office. Improvement. Processes. Customer experience. 
Os integrantes da Ouvidoria do Complexo Hospitalar Edmundo Vasconcelos buscaram a ABO (Associação Brasileira de Ouvidores) como referência para a sua estruturação, desde o curso para a capacitação até a participação em Congressos e outras atividades pertinentes ao desenvolvimento dos profissionais, sistematicamente promovidos pela $A B O$.

A Ouvidoria no Brasil surgiu após o fim da ditadura, em 1985, momento em que a sociedade civil clamava pela defesa de direitos e pelo exercício da liberdade e da organização (VISMONA; BARREIRO, 2015).

Foi inspirada no modelo de Ombudsman da Suécia, criado há mais de 200 anos, e se fortaleceu com a Constituição de 1988, que estabeleceu níveis democráticos de participação do cidadão. Pautado em princípios de cidadania, e com a criação do CDC (Código de Defesa do Consumidor) em 1990, foi possível criar um embrião daquilo que seria o modelo de Ouvidoria no Brasil, apoiado nas demandas de consumidores e usuários de produtos e serviços e se tornando a base do atendimento prestado pelas Ouvidorias no país (GUIA DE OUVIDORIAS BRASIL, 2011).

No Brasil, como defesa dos direitos dos cidadãos na esfera pública ou dos clientes na esfera privada, a Ouvidoria é, por resolução, obrigatória nas instituições financeiras desde 2007 e, a partir de 2013, também nas sociedades seguradoras, entidades abertas de previdência complementar e sociedades de capitalização, além das operadoras de planos privados de assistência à saúde (KALIL, 2013).

À medida que essa visão, frente aos direitos do cidadão, foi se ampliando no setor público, as empresas privadas começaram a perceber também que este era o melhor caminho. Aderiram à ideia de implantar Ouvidorias com base nos modelos existentes, com foco inicial em ouvir o cliente externo - era preciso abrir os olhos e aguçar os ouvidos (ALMEIDA, 2011).

Nos hospitais, com a introdução dos sistemas de Gestão de Qualidade e a busca pelos selos de acreditação, tendência mercadológica e competitiva, percebeu-se a necessidade de um canal para ouvir o cliente, haja vista a gama de informações extraídas das manifestações que possibilitam a melhoria dos processos, visando a segurança tanto dos pacientes quanto de colaboradores. Desta forma, os hospitais, independentemente de nomenclaturas, disponibilizaram este serviço, seja como SAC, Atendimento ao Cliente, Escritório de Experiência do Paciente, Coordenadoria de Hospitalidade, Gerência de Comunicação e Relacionamento com o Cliente, Diretoria de Intimidade com o Cliente ou Ouvidoria.

A percepção da qualidade varia de um cliente para outro, e não é a mesma para o comprador e fornecedor. Ademais, a qualidade de um serviço será percebida de maneira diferente se este for novo ou amplamente difundido, se o cliente o estiver descobrindo ou se for um usuário experiente (MARTINS, 2009).

Estrategicamente, a Ouvidoria contribui para a sustentabilidade da organização, pois ao tratar as reclamações de cada cliente, abre-se uma oportunidade para reconquistá-lo e fidelizá-lo, contribuindo para o aumento dos resultados da instituição; ao propor melhorias nos processos da empresa, evita que novas reclamações surjam, aumentando o grau de satisfação (KALIL, 2013).

Anteriormente, em nossa instituição, as manifestações eram coletadas pelos setores de Qualidade e Controladoria e direcionados à Diretoria, que demandava às áreas responsáveis, o que impossibilitava uma continuidade e tratativa multidisciplinar das manifestações apresentadas. A partir 
dessa situação, em 2011 foram iniciadas as atividades necessárias para elaboração de projeto, em conjunto com o setor de Qualidade, pautado em benchmarking com outras instituições de mesma natureza, a fim de estruturar um modelo que atendesse à nossa necessidade.

Com o objetivo de agregar valor à marca, criar um canal de comunicação e contemplar objetivos do Planejamento Estratégico 2020, nasceu a Ouvidoria do Complexo Hospitalar Edmundo Vasconcelos (CHEV).

Hoje, com a centralização das manifestações em uma única célula, a Ouvidoria contribui com a melhoria contínua dos processos, oferecendo à Diretoria e aos Gestores informações do cliente satisfeito e insatisfeito, suscitando que os pontos frágeis das áreas sejam repensados, contribuindo com a comunicação efetiva de gestores/equipes, fortalecendo as relações humanas, primordial para a obtenção de níveis de excelência na experiência do cliente.

Por tratar-se de um hospital reconhecido como centro de excelência médica - com 67 anos de vida, 220 leitos, 13 mil internações/ano, atuante em mais de 40 especialidades no Centro Médico de Especialidades, com 230 mil consultas/ano - e posicionar-se no ranking das Melhores Empresas Para Trabalhar do país pelo $6^{\circ}$ ano consecutivo e em $1^{\circ}$ lugar no ranking Saúde Hospitais 2016, ambos pelo Great Place to Work (GPTW), era necessário criar um canal regular de comunicação destinado ao cliente paciente/cliente acompanhante.

A Ouvidoria foi implantada em 2014, composta por 03 profissionais que atuam das $09 \mathrm{~h} 00$ às 17 h00 de segunda a sexta-feira. Conforme os habituais modelos de Ouvidoria, prevê uma Ficha de Análise de Manifestação, que recebe o registro da manifestação dos diversos canais de comunicação, como Sua Opinião (formulário disponível aos clientes), Fale Conosco (via site do hospital), Reclame Aqui, Telefone, Presencial, Seguradoras e Redes Sociais.

Apresentamos a seguir os resultados registrados nas Fichas Técnicas da Qualidade, preenchidas mensalmente, com análise bimestral com a Alta Direção e divulgação aos gestores, no período de 2014 a 2016.

\section{Total de manifestações}

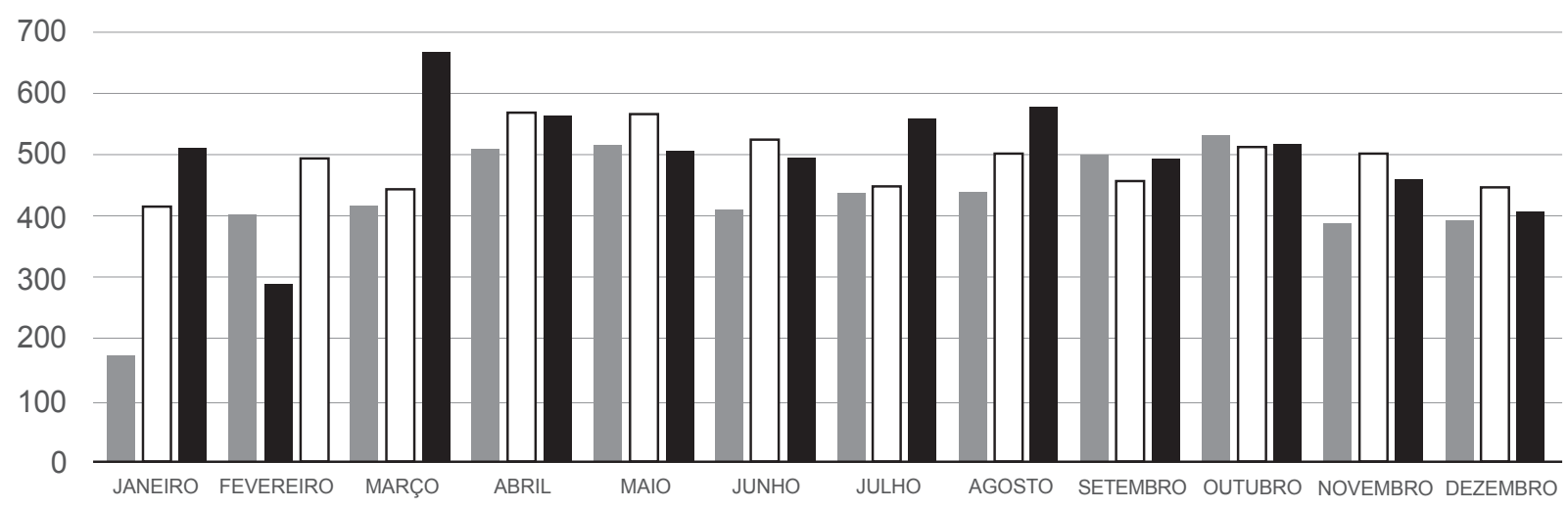

Fonte: Fichas técnicas, 2014, 2015 e 2016 
O aumento das manifestações está relacionado ao interesse do cliente em registrar a manifestação por ter ciência da existência do setor de Ouvidoria, divulgada no site do hospital e informada pelos funcionários, colaboradores e equipe médica.

A existência de um setor próprio para o registro de manifestações favorece a busca do cliente. A Ouvidoria é reconhecida como canal direto com a alta administração, bem como a resposta rápida para a solução de problemas.

De acordo com benchmarking realizado e participação no XVIII Congresso Brasileiro de Ouvidoria, foi verificada a mesma incidência de manifestações segundo a sua Classificação Técnica nas diversas Ouvidorias: item "Processos" seguido de "Pessoas".
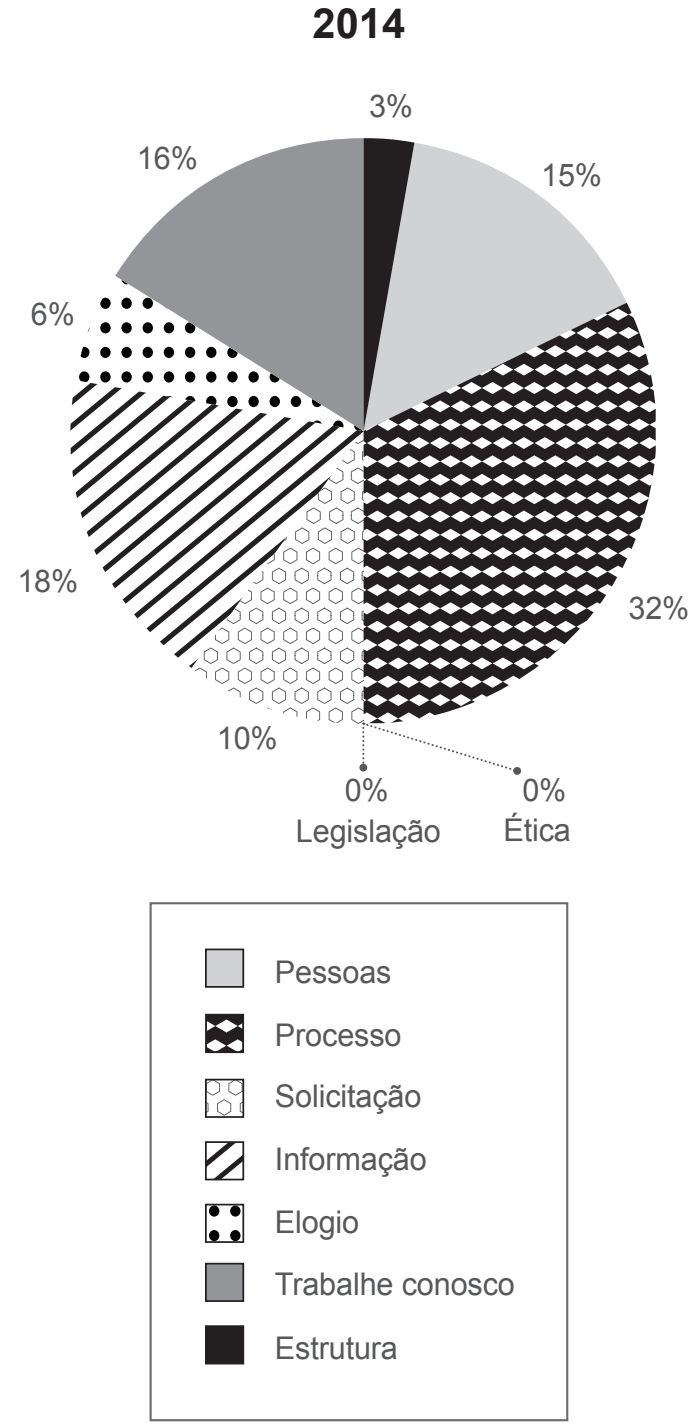

Fonte: Fichas técnicas 2014

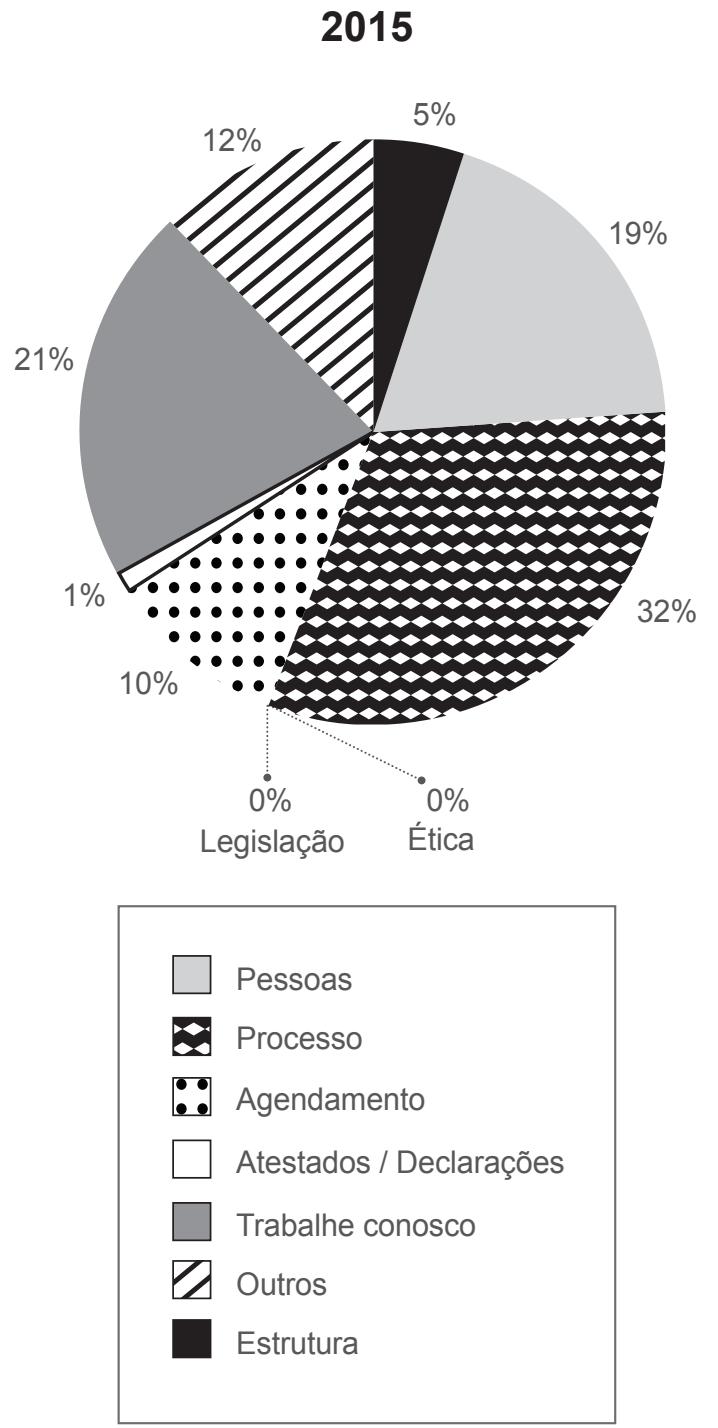

Fonte: Fichas técnicas 2015 


\section{6}
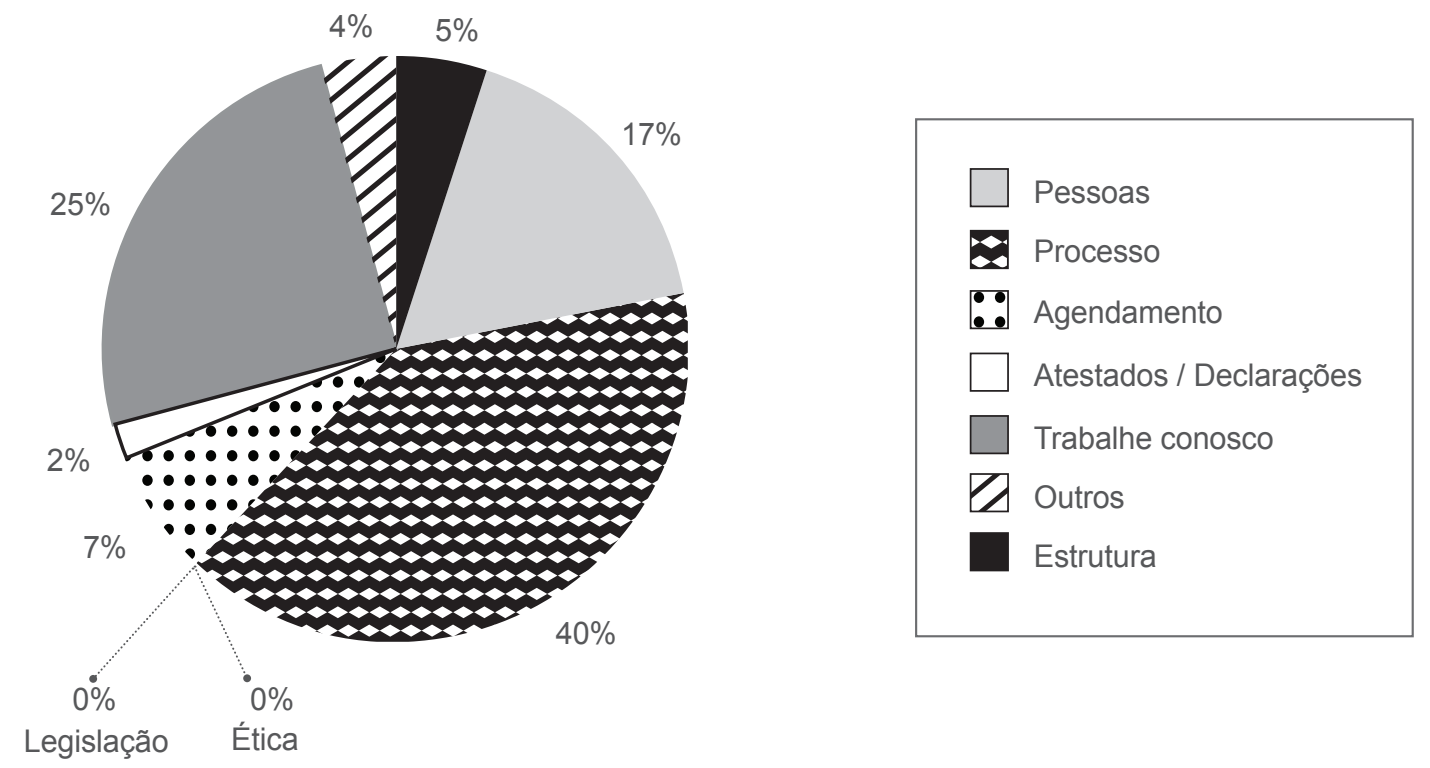

Fonte: Fichas técnicas 2016

As ações adotadas pelas áreas estão pautadas no alinhamento e na padronização não só de informações (procedimentos e processos), mas também de postura (pessoas), com foco no aprimoramento da comunicação e dos serviços prestados. Como ganho, as áreas são informadas de detalhes trazidos pelas manifestações, que a visão macro do processo não permitiria detectar.

A forma sistematizada da tratativa das manifestações resultou na aproximação das áreas, devido à necessidade do estreitamento da comunicação no momento da análise da situação apresentada.

A Ouvidoria comporta-se como uma forte aliada no processo de melhoria contínua, considerando o atual cenário competitivo, em que os consumidores contam com diversas opções de produtos e serviços, e o que faz a diferença é exatamente aquilo que não é palpável, como o aprimoramento das relações humanas, que converge para o conceito atual do Triple Aim (três metas), que visa melhorar a experiência com o cuidado, através de assistência segura, efetiva e confiável; diminuir os custos per capita e melhorar a saúde da população através de ações de prevenção, bem-estar e controle de condições crônicas. O Triple Aim atualmente considera uma quarta meta (Quadruple Aim), que contempla melhorar a experiência da prestação de cuidados em saúde, que em outras palavras significa garantir o engajamento da força de trabalho e se traduz em conseguir que os profissionais da área da saúde tenham alegria e significado no trabalho.

A grande aposta de valor é a busca pela diferenciação permanente, forçando um cenário de mudanças e inovações constantes. Notadamente o envio dos elogios, sistematizado pela Ouvidoria do $\mathrm{CHEV}$ aos médicos, funcionários e colaboradores, resulta na reflexão contínua so- 
bre o propósito, fortalecendo o sentimento de equipe bem como a busca pelo aprimoramento do desempenho profissional.

O desafio é sensibilizar os diferentes profissionais da saúde, quebrar alguns paradigmas, incentivar a adoção de comportamentos e atitudes que promovam o seu engajamento, visando a preservação das relações harmônicas em qualquer grupo de pessoas ou local e inspirar a transformação das situações de conflito, pois, afinal, não somos donos do cliente, mas donos do momento vivido por ele. A relação positiva com o cliente será pautada na capacidade de criar uma experiência diferenciada, capaz de marcar aquele momento na memória do consumidor.

\section{REFERÊNCIAS}

VISMONA, E. L.; BARREIRO, A. E. A. Ouvidoria brasileira - o cidadão e as instituições: edição comemorativa, 20 anos da ABO. São Paulo: Associação Brasileira de Ouvidores, 2015. 246 p.

GUIA DE OUVIDORIAS BRASIL. São Paulo: Padrão Editorial, 2011.

KALIL, E. Como implantar Ouvidoria e atuar nessa área. São Paulo: Trevisan, 2013. 136 p.

ALMEIDA, R. Abrindo os olhos e aguçando os ouvidos, 2011. Disponível em: http://www.abosaopaulo.org.br/artigo. php?codigo=31. Acesso em: 20 maio 2016, $10 \mathrm{~h} 30$.

MARTINS, R. O cliente sempre tem razão?, 2009. Disponível em: http://www.negociosdevalor.com.br/artigos_sobre_clientes_o_cliente_tem_sempre_razao.asp. Acesso em: 20 maio 2016, 09h50.

REVISTA CONSUMIDOR MODERNO. São Paulo: Padrão Editorial, 1996. Mensal. 20 anos construindo relações. ISSN 1413-1226. 